\title{
Physical Activity Status and Related Factors among Middle-Aged Women in West of Iran, Hamadan: A Cross-Sectional Study
}

\author{
Shohreh Emdadi ${ }^{1}$, Seyed Mohammad Mehdi Hazavehei ${ }^{2}$, Alireza Soltanian ${ }^{3}$, \\ Saeed Bashirian ${ }^{4} \&$ Rashid Heidari Moghadam ${ }^{5}$ \\ ${ }^{1}$ Department of Public Health, School of Health, Hamadan University of Medical Sciences, Hamadan, Iran \\ ${ }^{2}$ Research Center for Health Sciences and Department of Public Health, School of Health, Hamadan University of \\ Medical Sciences, Hamadan, Iran \\ ${ }^{3}$ Modeling of Non-Communicable Diseases Research Center and Department of Biostatistics, School of Public \\ Health, Hamadan University of Medical Sciences, Hamadan, Iran \\ ${ }^{4}$ Social Determinants of Health Research Center and Department of Public Health, School of Health, Hamadan \\ University of Medical Sciences, Hamadan, Iran \\ ${ }^{5}$ Research Center for Health Sciences and Department of Ergonomics, School of Health, Hamadan University of \\ Medical Sciences, Hamadan, Iran \\ Correspondence: Seyed Mohammad Mehdi Hazavehei, School of Health, Hamadan University of Medical \\ Sciences, Shahid Fahmideh Ave., Hamadan, Iran. Tel: 98-81-3838-0090. E-mail: Hazavehei@umsha.ac.ir
}

Received: August 16, 2015 Accepted: September 11, 2015 Online Published: February 24, 2016

doi:10.5539/gjhs.v8n10p151 URL: http://dx.doi.org/10.5539/gjhs.v8n10p151

\begin{abstract}
Physical inactivity is a major health problem in developing countries. Regular Physical Activity (RPA) can reduce the risk of many diseases such as cardiovascular disease, diabetes, and obesity that are prevalent in middle and old ages specifically in women. The (RPA) status among middle-aged Iranian women is not well known. The purpose of this study was to investigate the physical activity status and related factors among middle-aged women in Hamadan, a city in western Iran. The participants of this cross-sectional study were comprised of 866 middle-aged women in Hamadan who were selected using a proportional stratified random sampling method in 2015. The participants completed a self-administered questionnaire containing demographic characteristics and an International Physical Activity Questionnaire-Short Form (IPAQ-S). The data were analyzed with SPSS-16 software using Multi- nominal Logistic Regression. The results revealed that about $57 \%$ of the study population was inactive or not sufficiently active (light level). Additionally, the results showed that less than a quarter of the study participants (19.3\%) exhibited a severe level of physical activity. The associations between RPA and age, education level and job were significant $(\mathrm{P}<0.05)$. The chi-square test revealed a significant difference in RPA with regards to residency locations $(\mathrm{P}<0.05)$. The demographic variables relationship with physical activity appears to be important and these findings can be a prelude to design of effective intervention strategies in promoting physical activity.
\end{abstract}

Keywords: physical activity, middle-aged women, Iran

\section{Introduction}

One of the important contributors to a healthy lifestyle is the regular physical activity (RPA). Extensive research shows that people of all ages can improve their health with regular physical activity (WHO, 2010). Numerous study findings indicate that moderate physical activity can reduce the risk of and death from heart disease and can significantly influence hypertension, diabetes mellitus, osteoporosis, colon cancer and obesity (Abassi, 2015; Li, 2013; Rehn, 2013; WHO, 2010). Additionally, RPA can reduce levels of anxiety and depression and enhance self-esteem (USDHHS, 2008; Dashti, 2014). Furthermore, several epidemiological studies have shown that insufficient physical activity increases mortality rate (Pate et al., 1995; Dumith, 2011; WHO, 2010). RPA has also been associated with reduction of risk factors for the development of cerebral disease (Lee, 2003).

Other benefits of RPA can be measured financially through a reduction in long- term health and medical care costs. It has been reported that annually there is a direct increase in the cost of health care associated with inactivity for 
every single individual in Australia, the United kingdom and Switzerland ranging from $\$ 28.40$ to $\$ 334.40$ and indirect costs associated with inactivity ranging from $\$ 154.70$ to $\$ 418.90$ in the United States and Canada (Kohl et al., 2012).

Many researchers have emphasized on exercise and RPA as a way to strengthen the immune system and to reduce the occurrence of non-communicable diseases (Warburton et al., 2006). With regards to maintain one 's health through RPA, it has been estimated that adults need to devote their time to moderate to severe physical activity for 150 minutes per week or 5 days a week for half an hour a day (McClaran, 2003; WHO, 2014). The World Health Organization (WHO) considers Physical Activity any kind of body movement by skeletal muscles involving energy expenditure like as walking, jogging, dancing, extra (WHO, Uploaded January 2015).

Results of the Iranian national study published by WHO have shown that the prevalence of inactivity in urban and rural areas between men and women aged 15 years and older were $76 \%$ and $58.8 \%$, respectively and $67.5 \%$, in total within the same age group (Hazavehei et al., 2008). In some other studies, $80 \%$ of Iranians have been reported as inactive or having inadequate physical activity (Abassi, 2015; Sheikholeslam, 2004).

Women are more likely to develop diseases and disabilities arising from physiological reasons such as pregnancy, lactation and menopause than men. Postmenopausal women are faced reduced hormone levels and other issues (Janssen et al., 2010; Lewis et al., 2005) such as weight gain, bone loss (Lo et al., 2011), and increased risk of cardiovascular disease and hypertension (Berg \& Scherer, 2005; Matthews et al., 2009; Wajchenberg, 2000). RPA promotes health of skeletal system and improves women's health by offsetting to some degree, the negative effects of menopause (Baer et al., 2011; Eliassen et al., 2010). Another issue facing of older women is Vasomotor problems (Friedenreich, 2001; Kull, 2002; Lindh-Åstrand et al., 2004; Verloop et al., 2000) and it has been noted that regular and sustainable physical activity can prevent the development of physical and motor disabilities in women (Gretebeck, Ferraro, \& Black, 2012). The findings of the previous studies show that there is a strong relationship between physical activity with age, gender, employment status, education level and marital status (Abdi, 2015; Hazavehie et al., 2013). According to the findings, lack of physical activity is more common in women than in men and in older age groups (Hallal, 2012; Hawkins et al., 2009). It appears that physical activity in middle age, especially in middle-aged women, leads to lifestyle modifications that extend in to older ages and enhances their quality of life (Barg et al., 2012). The study of physical activity in different communities and social groups such as the middle aged populations helps planners and decision makers to identify patterns and factors of influencing these patterns and to initiate effective interventions. In considering this premise, the aim of this study was to evaluate the status of regular physical activity in middle-aged women and its related factors in the city of Hamadan. By evaluating the pattern of RPA amongst middle-aged women in Iran, an effective intervention in the lifestyle of middle-aged women in Iran and the nearby countries can be identified.

\section{Methods}

\subsection{Participants}

This cross-sectional study was performed among 866 middle-aged women who had been covered by 34 health centers in the city of Hamadan. The study was performed from the $15^{\text {th }}$ of December to the $5^{\text {th }}$ of April of 2015 in Hamadan. Participants were selected in various age groups $(40-44,45-49,50-54,55-59$, and 60-64) by proportional stratified sampling. So the number of participant in every age group is not equal. In every age group the participants were selected randomly from household files. The sample size with considering $\mathrm{P}=0.37$ and $\alpha=0.05$ and $\mathrm{d}=0.05$ and this formula $\left(\mathrm{n}=\left[(\mathrm{p} . \mathrm{q})\left(Z_{l-\alpha / 2}\right)^{2} /(\mathrm{d})^{2}\right]\right.$ ), with 1.5 coefficient for the effect clustering design. With assumption reliability of questionnaire as 0.7 the sample size was 852 .

This study was approved by the Ethics Committee of Hamadan University of Medical Sciences. Informed consent was obtained from all study participants before the start of the study. Researchers educated participants to ensure that they could reach a truly informed decision about whether or not to participate in the research.

\subsection{Measures}

A self-administered questionnaire included closed questions and required approximately 20 minutes to complete. The questionnaire included two sections: (a) demographic variebles: including age (year), weight $(\mathrm{kg})$, height (m),body mass index: BMI $\left(\mathrm{kg} / \mathrm{m}^{2}\right)$, marital status, educational level, job, number of children. (b) Physical activity behavior which was measured with the Persian-translated form of the International Physical Activity Questionnaire-Short Form (IPAQ-S). The IPAQ assessed the physical activity during the past 7 days and based upon the final score, determined the intensity of the activity. The participants were then classified into three categories: light, moderate, and severe (Questionnaire(IPAQ). 2005, Hazavehie et al., 2013). Total intensity during the last 7 days was calculated as the IPAQ protocol. Low-intensity physical activity was considered when 
consumption was lower than 600 MET-minutes/week, if the consumption was between 600 to 3000 MET-minutes/week physical activity was considered moderate, but any consumption above 3000 MET-minutes/week signified physical activity in the high or severe category (Craig, 2003).

\subsection{Data Analysis}

All analyses were conducted using SPSS-16. After data cleaning, descriptive analyses were conducted using means and standard deviations. Demographic variables and RPA levels were reported as frequency and percentages. Subgroup comparisons were conducted using Multi-nominal Logistic Regression. In addition, a p-value of 0.05 or less was considered statistically significant.

\section{Results}

The results were obtained from completed questionnaires submitted by 866 women. The age of respondents ranged from 40 to 64 years, with a mean age of 49.82 years $(\mathrm{SD}=6.91)$. The most number of women were in the 40-44year- age group at $28.9 \%$. Regarding the educational status, $9.8 \%$ of respondents were illiterate, $13.1 \%$ had completed primary school only, $21.4 \%$ had completed secondary school, $24.6 \%$ had completed high school, and $31.1 \%$ had completed some college level curriculum or more (post-high school). In relation to job status, $72.9 \%$ of participants were housewives. More details of demographic characteristics of the participants are listed in Table 1.

Table 1. Demographic characteristics of middle-aged women $(\mathrm{n}=866)$

\begin{tabular}{|c|c|c|c|}
\hline Variables & & Frequency & Percent \\
\hline \multirow{5}{*}{ Age (yr) } & $40-44$ & 250 & $28.9 \%$ \\
\hline & $45-49$ & 199 & $23 \%$ \\
\hline & $50-54$ & 176 & $20.3 \%$ \\
\hline & $55-59$ & 143 & $16.5 \%$ \\
\hline & $60-64$ & 98 & $11.3 \%$ \\
\hline \multirow{5}{*}{ Education } & Illiterate & 85 & $9.8 \%$ \\
\hline & Primary & 114 & $13.1 \%$ \\
\hline & Secondary & 185 & $21.4 \%$ \\
\hline & High school & 213 & $24.6 \%$ \\
\hline & Academic & 269 & $31.1 \%$ \\
\hline \multirow{2}{*}{ Job Status } & Housewife & 631 & $72.9 \%$ \\
\hline & Employee & 235 & $27.1 \%$ \\
\hline \multirow{4}{*}{ Number of Children } & No child & 124 & $14.3 \%$ \\
\hline & 1-2 children & 427 & $49.3 \%$ \\
\hline & 3-5 children & 298 & $34.4 \%$ \\
\hline & $6<$ & 17 & $2 \%$ \\
\hline \multirow{4}{*}{ BMI } & $<19.9$ & 12 & $1.4 \%$ \\
\hline & $20-24.9$ & 291 & $33.6 \%$ \\
\hline & $25-29.9$ & 484 & $55.9 \%$ \\
\hline & $30<$ & 79 & $9.1 \%$ \\
\hline \multirow{3}{*}{ Marital Status } & Married & 705 & $81.4 \%$ \\
\hline & Unmarried & 54 & $6.2 \%$ \\
\hline & Separated & 107 & $12.4 \%$ \\
\hline
\end{tabular}

Regarding frequency of RPA status, a number of 493 women (56.9\%) were involved in light levels of physical activity, and 206 (23.8\%) and 167 (19.3\%) women were involved in moderate and severe levels of physical activity, respectively. 


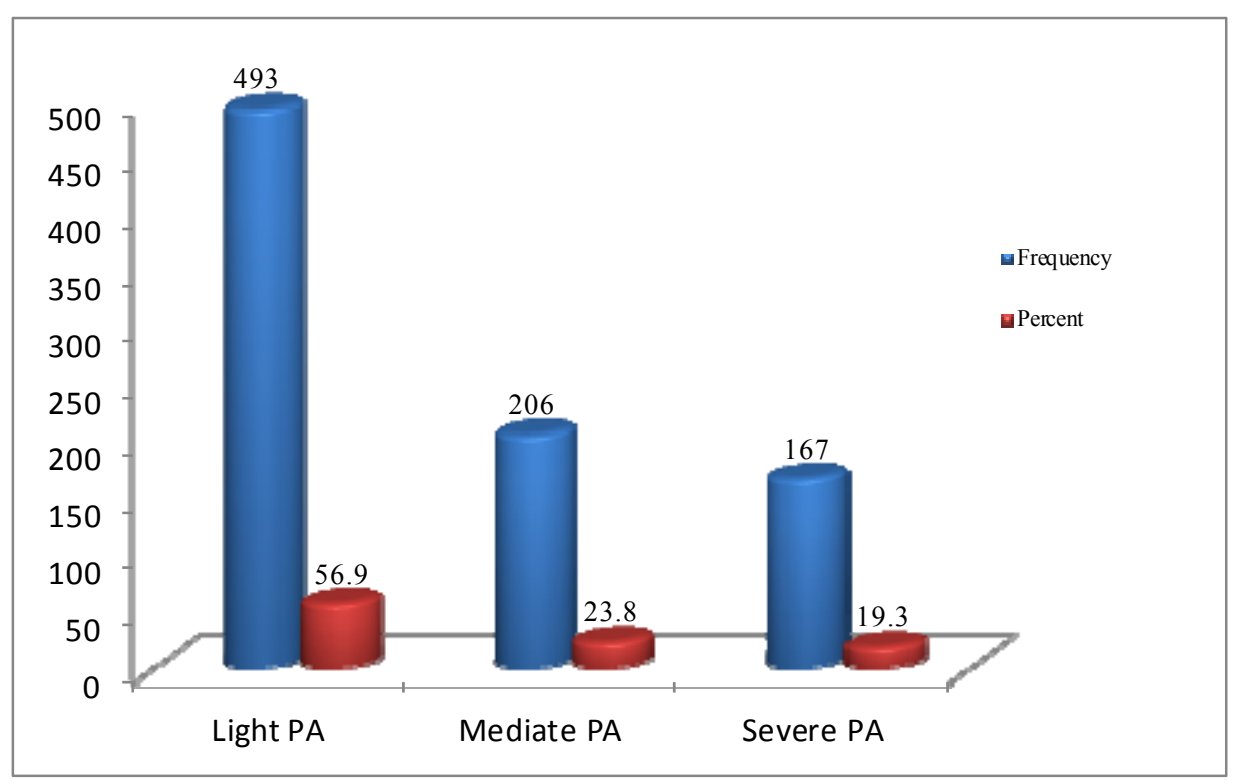

Figure 1. Frequency distribution of RPA levels among middle-aged women $(\mathrm{n}=866)$

Figure 2 illustrates the distribution of light level of RPA in the different part of Hamadan. The Chi-square test regards that, there is a significant difference in RPA based upon residency locations $(\mathrm{P}<0.05)$. As noted in Figure 2 the light level of RPA is divided in to three groups: (a) locales where $<50 \%$ women were engaged in light RPA,(b) locales where $50-70 \%$ women were engaged in light RPA, and (c) locales where $>70 \%$ women were engaged light RPA. It appears that means that the Figure 2 corresponds belong to inactive or not sufficiently active middle-aged women in Hamadan living in mostly areas far from the center of the city.

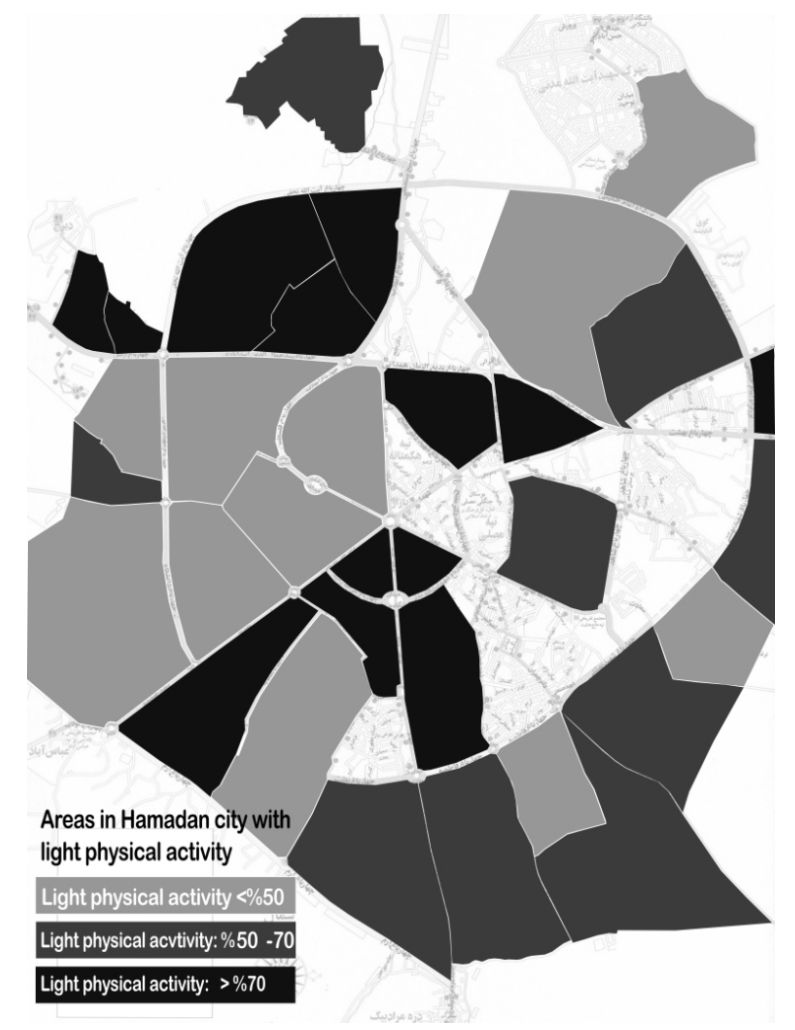

Figure 2. Distribution of light level of RPA in the different part of Hamadan city 
Table 2 shows the association between the demographics variables and RPA. The associations between RPA levels and age, education level, and job status were significant $(\mathrm{P}<0.05)$. However, there was no association between RPA and the number of children or with BMI or with marital status $(\mathrm{P}>0.05)$. The Multi- nominal Logistic Regression analysis revealed that with regards to increasing age, the incidence of moderate or severe RPA as compared to the incidence light RPA decreased. According to the result, only post-high school education had a higher incidence for moderate RPA ( $\mathrm{p}=0.006)$. Furthermore, the results showed that middle-aged women who were employed were significantly more physically active than counterparts who were housewives $(\mathrm{P}<0.001)$.

Table 2. Association between RPA levels and demographic characteristics of middle-aged women with multi-nominal logistic regression model ${ }^{\mathrm{a}}$

\begin{tabular}{|c|c|c|c|c|c|c|c|c|}
\hline \multirow[t]{2}{*}{ Variables } & & \multirow{2}{*}{$\underset{(n=493)^{b}}{\text { Light }} P A$} & \multirow{2}{*}{$\begin{array}{l}\text { Moderate } \\
P A(n=206)^{a}\end{array}$} & \multirow{2}{*}{$\begin{array}{l}\text { Severe PA } \\
(n=167)^{a}\end{array}$} & \multicolumn{2}{|c|}{$\begin{array}{l}\text { Moderate } \\
\text { light PA }\end{array}$} & \multicolumn{2}{|c|}{$\begin{array}{ll}\text { Severe } & \text { versus } \\
\text { light PA } & \end{array}$} \\
\hline & & & & & OR & $\mathbf{P}$ & OR & $\mathbf{P}$ \\
\hline \multirow{5}{*}{ Age $(y r)$} & $40-44$ & $120(48 \%)$ & $58(23.2 \%)$ & $72(28.8 \%)$ & 1.77 & 0.092 & 6.24 & $<0.001$ \\
\hline & $45-49$ & $108(54.3 \%)$ & $44(22.1 \%)$ & $47(23.6 \%)$ & 1.57 & 0.184 & 4.87 & 0.001 \\
\hline & $50-54$ & $100(56.7 \%)$ & $54(30.7 \%)$ & $22(12.5 \%)$ & 2.32 & 0.013 & 2.56 & 0.059 \\
\hline & $55-59$ & $92(64.3 \%)$ & $33(23.1 \%)$ & $18(12.6 \%)$ & 1.44 & 0.307 & 2.17 & 0.124 \\
\hline & $60-64$ & $73(74.5 \%)$ & $17(17.3 \%)$ & $8(8.2 \%)$ & ------ & ------ & ------ & --------- \\
\hline \multirow{5}{*}{ Education } & Illiterate & $56(65.9 \%)$ & $15(17.6 \%)$ & $14(16.5 \%)$ & 0.577 & 0.131 & 1.53 & 0.298 \\
\hline & Primary & $63(55.3 \%)$ & $26(22.8 \%)$ & $25(21.9 \%)$ & 0.764 & 0.391 & 1.89 & 0.073 \\
\hline & Secondary & $110(59.4 \%)$ & $39(21.1 \%)$ & $36(19.5 \%)$ & 0.636 & 0.089 & 1.67 & 0.104 \\
\hline & $\begin{array}{l}\text { High } \\
\text { School }\end{array}$ & $138(64.8 \%)$ & $47(22.1 \%)$ & $28(13.1 \%)$ & 0.507 & 0.006 & 0.67 & 0.173 \\
\hline & Academic & $126(46.8 \%)$ & $79(29.4 \%)$ & $64(23.8 \%)$ & ------ & -- & --- & --------- \\
\hline \multirow{4}{*}{ BMI } & $>19.9$ & $4(33.3 \%)$ & $4(33.3 \%)$ & $4(33.4 \%)$ & 2.11 & 0.108 & 1.34 & 0.757 \\
\hline & $20-24.9$ & $164(56.3 \%)$ & $73(25.1 \%)$ & $54(18.6 \%)$ & 1.28 & 0.482 & 0.918 & 0.826 \\
\hline & $25-29.9$ & $275(56.9 \%)$ & $113(23.3 \%)$ & $96(19.8 \%)$ & 1.15 & 0.667 & 1.19 & 0.63 \\
\hline & $30<$ & $50(63.2 \%)$ & $16(20.3 \%)$ & $13(16.5 \%)$ & ------- & -------- & ------- & ------- \\
\hline \multirow{2}{*}{ Job status } & Employee & $98(41.7 \%)$ & $53(22.6 \%)$ & $84(35.7 \%)$ & 0.922 & 0.719 & 0.22 & $<0.001$ \\
\hline & House wife & $395(62.6 \%)$ & $153(24.2 \%)$ & $83(13.2 \%)$ & ------ & -------- & ------- & ------- \\
\hline \multirow{4}{*}{$\begin{array}{l}\text { Number of } \\
\text { children }\end{array}$} & No-child & $59(47.6 \%)$ & $29(23.4 \%)$ & $36(29 \%)$ & 1.73 & 0.526 & 1.68 & 0.553 \\
\hline & 1-2 child & $232(54.3 \%)$ & $112(26.3 \%)$ & $83(19.4 \%)$ & 2.12 & 0.358 & 0.772 & 0.759 \\
\hline & 3-4 child & $189(63.4 \%)$ & $63(21.2 \%)$ & $46(15.4 \%)$ & 1.7 & 0.514 & 0.765 & 0.75 \\
\hline & $6<$ & $13(76.4 \%)$ & $2(11.8 \%)$ & $2(11.8 \%)$ & ---- & ---------- & -------- & -----. \\
\hline \multirow{3}{*}{$\begin{array}{l}\text { Marital } \\
\text { status }\end{array}$} & Married & $415(58.9 \%)$ & $161(22.8 \%)$ & $129(18.3 \%)$ & 0.605 & 0.061 & 0.673 & 0.192 \\
\hline & Unmarried & $27(50 \%)$ & $15(27.8 \%)$ & $12(22.2 \%)$ & 0.669 & 0.4 & 0.33 & 0.035 \\
\hline & Separated & $51(47.7 \%)$ & $30(28 \%)$ & $26(24.3 \%)$ & ---------- & ------ & -------- & --------- \\
\hline
\end{tabular}

${ }^{\mathrm{a}}$ Model fitting information of a relationship between the dependent variable and combination of independent variables is less than 0.001

${ }^{\mathrm{b}}$ All values are presented as $\mathrm{n}(\%)$.

\section{Discussion}

The aim of this study was to determine the status of RPA and its related factors among middle-aged women in Hamadan. According to the findings, it appears that physical activity of more than half of the middle-aged women in this study is insufficient (light level) and irregular. These findings are consistent with the results of similar studies performed earlier. For example, the global level of inactivity has been reported to be about $58 \%$ (USDHHS, 2008). The results of an earlier study also showed that the prevalence of inactivity in the population above the age of 20 in Tehran was $69.8 \%$ (Momenan et al., 2011). This rate has been reported $80 \%$ in the study by Sheikholeslam (Sheikholeslam, 2004). In another study (Hazavehie et al., 2013) the reported rate of physical inactivity among employed women in Hamadan was $80 \%$.In the study by Jalilian et al, the rate of inactivity was $65 \%$ among women 
in Hamadan (Jalilian et al., 2011). It appears that physical inactivity is a strong contributor to health problems in Iranian society, particularly amongst women. Identifying the barriers to regular physical activity leads to the adoption of appropriate education strategies to promote the health of the middle-aged population particularly women.

The results of the present study reveal that there is a significant relationship between RPA and demographic variables, including age, education and employment status. One study in Iran showed that age was related with physical activity and the level of physical activity decreased with increasing age (Momenan et al., 2011). Similar findings have also been reported in other studies (Abdi, 2015; Bergman, 2008; Hawkins et al., 2009). It appears that with increasing age and the incidence of motor disorders and non-communicable diseases, the level of RPA decreases and health planner and authorities need to pay close attention to this important issue.

The results of this study point to an increased level of physical activity increasing education (years). Study participant with academic (post-high school) education had a higher likelihood of participating in moderate RPA as compared to high school level study participants $(\mathrm{P}=0.006)$.

These findings of this study are consistent with other studies that obtained similar results (Abassi, 2015; Gaston \& Cramp, 2011; Jalilian et al., 2011; Momenan et al., 2011). In the study by Salehi et al, one of the facilitators of physical activity was awareness of the benefits of physical activity (Salehi et al., 2010). It appears that the awareness of the benefits of physical activity leads to improved attitude and motivation among women, which also increases the intention to performed physical activity (Abdi, 2015) .

This study also revealed that women who were, employed performed higher levels of physical activity. The finding is consistent with similar studies (Hazavehie et al., 2013; Jalilian et al., 2011). The participation of women in society and acceptance of social responsibility leads to greater communication, information gain, and increased self-efficacy and self-esteem of women and this in turn will lead to increased physical activity. It is worth noting the relationship between self-efficacy and physical activity has been reported in previous studies (Hashemi et al., 2013).

In this study, there was a significant relationship between physical activity and geographic residency. People who lived in city centers were engaged in more physical activity as compared to others who were living far from center. Relevant factors that contributed to this increased RPA included the ban on the use of private automobiles in the city centers, walking to perform daily activities and of numerous sports facilities and gymnasiums in the city center. In similar studies, access to sports facilities, sport stadium and gymnasiums has been reported as enabling factors to performing physical activity (Hazavehie et al., 2013; Jalilian et al., 2011; Moeini B, 2011). It appears that providing a safe and appropriate environment to women for walking and other exercises and provides them easy access to sports equipment leads to higher levels of physical activity (RPA) among women.

This study was limited in that was a cross-sectional study. Additionally, the obtained information was based on the self reporting assessment of physical activity behavior of the study participants.

\section{Conclusion}

The result of this study revealed that, about $57 \%$ of women in this study were inactive or not sufficiently active (light level). Recognition of this lack of sufficient activity in groups and communities (middle-aged women in Hamadan) help better planning and interventions to promote physical activity among them. Status of RPA among groups of women in different ages and different places is good to focus on them with appropriate program.

\section{Acknowledgements}

This study is part of a dissertation for the health education and health promotion $\mathrm{PhD}$ degree (No. 9310095145). Dissertation support was provided from the Health Sciences Research Center of Medical Sciences University of Hamadan \& The vice chancellor for Research and Technology.

\section{Conflict of Interest}

The authors declare that there is no conflict of interests regarding the publication of this paper.

\section{References}

Abassi, M. B. M. S. Z., \& Vakili, V. (2015). A Trans-Theoretical Approach to Physical Activity Profile in General Population of Mashhad. Global Journal of Health Science, 7, 46-53. http://dx.doi.org/10.5539/gjhs.v7n7p46

Abdi, J. E. H., Mahmoodi, M., Shojayzadeh, D., \& Sadeghi, R. (2015). Physical Activity Status And Position Of Governmental Employees In Changing Stage Based On The Trans-Theoretical Model In Hamadan. Global Journal of Health Science, 7, 23-32. http://dx.doi.org/10.5539/gjhs.v7n5p23 
Baer, H. J., Glynn, R. J., Hu, F. B., Hankinson, S. E., Willett, W. C., Colditz, G. A., ... Rosner, B. (2011). Risk Factors for Mortality in the Nurses' Health Study: A Competing Risks Analysis. American Journal of Epidemiology, 173, 319-329. http://dx.doi.org/10.1093/aje/kwq368

Barg, C. J., Latimer, A. E., Pomery, E. A., Rivers, S. E., Rench, T. A., Prapavessis, H., \& Salovey, P. (2012). Examining Predictors of Physical Activity among Inactive Middle-Aged Women: An Application of the Health Action Process Approach. Psychology \& Health, 27, 829-845. http://dx.doi.org/10.1080/08870446. 2011.609595

Berg, A. H., \& Scherer, P. E. (2005). Adipose Tissue, Inflammation, and Cardiovascular Disease. Circulation Research, 96, 939-949. http://dx.doi.org/10.1161/01.RES.0000163635.62927.34

Bergman, P. G. A., Hagstromer, M., Bauman, A., \& Sjostrom, M. (2008). Adherence To Physical Activity Recommendations And The Influence Of Socio-Demographic Correlates-A Population Based Cross-Sectional Study. Bmc Public Health, 8, 367. http://dx.doi.org/10.1186/1471-2458-8-367

Craig, C. M. A., Sjostrom, M., Bauman, A., Booth, M., Ainsworth, B., et al. (2003). International Physical Activity Questionnaire: 12-Country Reliability and Validity. Med Sci Sports Exerc., 35, 1381-95. http://dx.doi.org/10. 1249/01.MSS.0000078924.61453.FB

Dashti, S. S. T. T., Jafarzadeh, E. A., \& Jafarzadeh, E. R. (2014). Effect of Physical Activity Level on Emotional Status of Iranian Women. World Applied Sciences Journal, 30, 852-857.

Dumith, S. H. P., Reis, R., \& Kohl, I. H. (2011). Worldwide Prevalence of Physical Inactivity and Its Association with Human Development Index in 76 Countries. Preventive Medicine, 53, 24-28. http://dx.doi.org/10. 1016/j.ypmed.2011.02.017

Eliassen, A. H., Hankinson, S. E., Rosner, B., Holmes, M. D., \& Willett, W. C. (2010). Physical Activity and Risk of Breast Cancer among Postmenopausal Women. Archives of Internal Medicine, 170, 1758-1764. http://dx.doi.org/10.1001/archinternmed.2010.363

Friedenreich, C. M. (2001). Physical Activity And Cancer: Lessons Learned From Nutritional Epidemiology. Nutrition Reviews, 59, 349-357. http://dx.doi.org/10.1111/j.1753-4887.2001.tb06962.x

Gaston, A., \& Cramp, A. (2011). Exercise During Pregnancy: A Review Of Patterns And Determinants. Journal of Science and Medicine in Sport, 14, 299-305. http://dx.doi.org/10.1016/j.jsams.2011.02.006

Hallal, P. A. L., Bull, F., Guthold, R., Haskell, W., \& Ekelund, U. (2012). Global Physical Activity Levels; Surveillance Progress .Pitfalls And Prospects. Lancet, 380, 247-257. http://dx.doi.org/10.1016/S0140 $-6736(12) 60646-1$

Hashemi, S. Z., Rakhshani, F., Keykhaei, R., Zareban, I., \& Tizvir, A. (2013). Relationship between Self-Efficacy with Physical Activity Stages of Change in Housewives.

Hawkins, M. S., Storti, K. L., Richardson, C. R., King, W. C., Strath, S. J., Holleman, R. G., \& Kriska, A. M. (2009). Objectively Measured Physical Activity Of USA Adults By Sex, Age And Racial/Ethnic Groups: A Cross-Sectional Study. International Journal of Behavioral Nutrition and Physical Activity, 6. http://dx.doi.org/10.1186/1479-5868-6-31

Hazavehei, S. M. M., Asadi, Z., Hassanzadeh, A., \& Shekarchizadeh, P. (2008). Comparing The Effect Of Two Methods Of Presenting Physical Education П Course On The Attitudes And Practices Of Female Students Towards Regular Physical Activity In Isfahan University Of Medical Sciences. Iranian Journal of Medical Education, 8, 121-131.

Hazavehie, S. M. M., Otogara, M., Moeini, B., Roshanaei, G., \& Kafami, V. (2013). Physical Activity And Its Related Factors Among Female Employees: Applying Basnef Model. Journal of Research \& Health, 3, 551-557.

Jalilian, F., Emdadi, S., Mirzaie, M., \& Barati, M. (2011). The Survey Physical Activity Status of Employed Women in Hamadan University of Medical Sciences: The Relationship between the Benefits, Barriers, Self-Efficacy and Stages of Change.

Janssen, I., Powell, L. H., Kazlauskaite, R., \& Dugan, S. A. (2010). Testosterone and Visceral Fat in Midlife Women: The Study of Women's Health across the Nation (Swan) Fat Patterning Study. Obesity, 18, 604-610. http://dx.doi.org/10.1038/oby.2009.251

Kohl, H. W., Craig, C. L., Lambert, E. V., Inoue, S., Alkandari, J. R., Leetongin, G., ... Group, L. P. A. S. W. (2012). The Pandemic of Physical Inactivity: Global Action for Public Health. The Lancet, 380, 294-305. 
http://dx.doi.org/10.1016/S0140-6736(12)60898-8

Kull, M. (2002). The Relationships between Physical Activity, Health Status and Psychological Well-Being of Fertility-Aged Women. Scandinavian Journal of Medicine \& Science in Sports, 12, 241-247. http://dx.doi.org/10.1034/j.1600-0838.2002.00341.x

Lee, C. F. A., \& Blair, S. (2003). Physical Activity and Stroke Risk: A Meta -Analysis. Stroke, 34, 2475-81. http://dx.doi.org/10.1161/01.STR.0000091843.02517.9D

Lewis, T. T., Everson-Rose, S. A., Sternfeld, B., Karavolos, K., Wesley, D., \& Powell, L. H. (2005). Race, Education, and Weight Change in a Biracial Sample of Women at Midlife. Archives of Internal Medicine, 165, 545-551. http://dx.doi.org/10.1001/archinte.165.5.545

Li, J. S. J. (2013). Physical Activity and Risk of Cardiovascular Disease- A Meta -Analysis of Prospective Cohort Studies. International Journal of Environmental Research and Public Health, 9, 391. http://dx.doi.org/10. 3390/ijerph9020391

Lindh-Åstrand, L., Nedstrand, E., Wyon, Y., \& Hammar, M. (2004). Vasomotor Symptoms and Quality of Life in Previously Sedentary Postmenopausal Women Randomized to Physical Activity or Estrogen Therapy. Maturitas, 48, 97-105. http://dx.doi.org/10.1016/S0378-5122(03)00187-7

Lo, J. C., Burnett-Bowie, S.-A. M., \& Finkelstein, J. S. (2011). Bone and the Pre-Menopause. Obstetrics and Gynecology Clinics of North America, 38, 503-517. http://dx.doi.org/10.1016/j.ogc.2011.07.001

Matthews, K. A., Crawford, S. L., Chae, C. U., Everson-Rose, S. A., Sowers, M. F., Sternfeld, B., \& Sutton-Tyrrell, K. (2009). Are Changes In Cardiovascular Disease Risk Factors In Midlife Women Due To Chronological Aging Or To The Menopausal Transition? Journal of the American College of Cardiology, 54, 2366-2373. http://dx.doi.org/10.1016/j.jacc.2009.10.009

Mcclaran, S. R. (2003). The Effectiveness of Personal Training on Changing Attitudes towards Physical Activity. Journal of Sports Science \& Medicine, 2, 10.

Moeini, B. J. F., Jallilian, M., \& Barati, M. (2011). Predicting Factors Associated with Regular Activity among College Students Applying Basnef Model. Sci J Hamadan Univ Med Sci, 18, 70-76.

Momenan, A. A., Delshad, M., Mirmiran, P., Ghanbarian, A., \& Azizi, F. (2011). Leisure Time Physical Activity and Its Determinants among Adults in Tehran: Tehran Lipid and Glucose Study. International Journal of Preventive Medicine, 2, 243.

Pate, R. R., Pratt, M., Blair, S. N., Haskell, W. L., Macera, C. A., Bouchard, C., ... King, A. C. (1995). Physical Activity and Public Health: A Recommendation from the Centers for Disease Control and Prevention and the American College of Sports Medicine. Jama, 273, 402-407. http://dx.doi.org/10.1001/jama.1995.0352 0290054029

Questionnaire (Ipaq), I. P. A. (2005). Guidelines for Data Processing and Analysis.

Rehn Ta, W. R., Wisloff, U., \& Rognmo, O. (2013). Increasing Physical Activity of High Intensity to Reduce the Prevalence of Chronic Disease and Improve Public Health. Open Cardiovasc Med J, 7, 1-8. http://dx.doi.org/10.2174/1874192401307010001

Salehi, L., Taghdisi, M., Ghasemi, H., \& Shokervash, B. (2010). To Identify the Facilitator and Barrier Factors of Physical Activity among Elderly People in Tehran. Iranian Journal of Epidemiology, 6, 7-15.

Sheikholeslam, R. M. A., Mohammad, K., \& Vaseghi, S. (2004). Non Communicable Disease Risk Factors in Iran. Asia Pac J Clin Nutr, 13, 125-130.

Usdhhs, U. D. O. H. A. H. S. P. A. G. A. C. (2008). Physical Activity Guidelines Advisory Committee Report, 2008. Department Of Health And Human Services, A1-H14. Washington, DC: US.

Verloop, J., Rookus, M. A., Van Der Kooy, K., \& Van Leeuwen, F. E. (2000). Physical Activity and Breast Cancer Risk in Women Aged 20-54 Years. Journal of the National Cancer Institute, 92, 128-135. http://dx.doi.org/10.1093/jnci/92.2.128

Wajchenberg, B. L. (2000). Subcutaneous and Visceral Adipose Tissue: Their Relation to the Metabolic Syndrome. Endocrine Reviews, 21, 697-738. http://dx.doi.org/10.1210/edrv.21.6.0415

Warburton, D. E., Nicol, C. W., \& Bredin, S. S. (2006). Health Benefits of Physical Activity: The Evidence. Canadian Medical Association Journal, 174, 801-809. http://dx.doi.org/10.1503/cmaj.051351

WHO 2010. Global recommendation physical activity for health. 
WHO 2014. Physical Activity. Fact sheet N 385.

WHO Uploaded January 2015. Physical Activity. Retrieved from http://www.who.int/mediacentre/factsheets/ fs $385 /$ en/

\section{Copyrights}

Copyright for this article is retained by the author(s), with first publication rights granted to the journal.

This is an open-access article distributed under the terms and conditions of the Creative Commons Attribution license (http://creativecommons.org/licenses/by/3.0/). 